\title{
"A CIDADE FOI REPARTIDA E NÓS NÃO FOMOS CONVIDADOS": AÇÃO COLETIVA E A CONSTRUÇÃO DE UMA NOÇÃO DE CIDADE NO COLETIVO DEBAIXO
}

\author{
"The city was shared and we weren't invited": collective action \\ and the construction of a notion of a city in the Debaixo \\ Collective. \\ "La ciudad fue repartida y no fuimos invitados": acción colectiva \\ y construcción de una idea de ciudad en el Coletivo Debaixo.
}

JONATHA VASCONCELOS SANTOS I*

WILSON JOSÉ FERREIRA DE OLIVEIRA ${ }^{I^{* * *}}$

http://dx.doi.org/10.1590/S2178-14942018000300008

\footnotetext{
' Universidade Federal de Sergipe (UFS), Aracaju - SE, Brasil.

*Doutorando em Sociologia pela Universidade Federal de Sergipe. (vasconcelos.jonatha@gmail.com)

"Universidade Federal do Rio Grande do Sul (UFRGS), Porto Alegre - RGS, Brasil.

* *Doutor em Antropologia Social pela Universidade Federal do Rio Grande do Sul (UFRGS). Professor Associado 3 da Universidade Federal de Sergipe (UFS), no Departamento de Ciências Sociais (DCS), no Programa de Pós-graduação em Sociologia (PPGS) e no Programa de Pós-graduação em Antropologia (PPGA). (etnografia.politica@gmail.com)
}

Artigo recebido em $1^{\circ}$ de junho de 2018 e aceito para publicação em 10 de setembro de 2018. 


\title{
RESUMO
}

Este artigo tem o objetivo de analisar o processo de construção de uma noção de cidade pelo Coletivo Debaixo e sua atuação em torno da pauta do "direito à cidade" entre os anos de 2013 e 2016 em Aracaju. Para isso, analisamos os fanzines publicados pelo coletivo para a difusão da causa. Nesse sentido, o trabalho demonstra o processo de tradução local elaborado pelo Coletivo em torno da ideia de uma cidade enquanto problema social e um espaço político cuja disputa pode ser através do uso da ocupação cultural.

\section{PALAVRAS-CHAVE: Coletiva, Direito à cidade; Ocupação altural; Movimentos sociais.}

\begin{abstract}
This article aims to analyze the process of constructing a notion of a city by the Coletivo Debaixo and its work on the "right to the city" agenda between 2013 and 2016 in Aracaju. For this, we use as empirical reference the fanzines published by the collective for the diffusion of the cause. In this sense, the work demonstrates the local translation process elaborated by the collective around the idea of a city as a social problem and a political space whose dispute can be through the use of cultural occupation.
\end{abstract}

KEYWORDS: Collective; Right to the city, Cultural occupation; Social movements.

\section{RESUMEN}

El artículo tiene el objetivo de analizar el proceso de construcción de una noción de ciudad por el Coletivo Debaixo y su actuación en torno a la pauta del "derecho a la ciudad" entre los años de 2013 y 2016 en Aracaju. Para ello, utilizamos como referencial empíricos los fanzines publicados por el colectivo para la difusión de la causa. En este sentido, el trabajo demuestra el proceso de traducción local elaborado por el colectivo en torno a la idea de una ciudad como problema social y un espacio político cuya disputa puede ser a través del uso de la ocupación cultural.

PALABRAS CLAVE: Colectiva Deredho a la dudad; Ocupadón aultural; Movimientos sodiales. 


\section{INTRODUÇÃO}

trajetória dos estudos sobre movimentos sociais e formas de protestos e contesta-
çáo debruçado sobre diversos problemas teóricos e metodológicos e originado agendas de pesquisa bem variadas. Dentre estas, cabe destacar as que se referem às oportunidades e aos constrangimentos para a ação coletiva, à caracterização dos repertórios de ação, aos modelos de organização, ao desenvolvimento de redes de movimentos sociais e aos processos de construção de atores engajados (Alonso, 2009; Gohn, 2014; Diani, 1992; Diani, Della Porta, 2006; Oliveira, 2010, 2013). Diante disso, a análise do processo de criação e difusão de "enquadramentos interpretativos" da ação coletiva tem recebido uma atenção renovada recentemente, sendo articulada com questões relativas à apreensão de uma gramática ou das "gramáticas políticas" das mobilizações e lutas coletivas (Benford, 1997; Benford, Snow, 2000; Silva, Cotanda, Pereira, 2017). Em consonância com essa renovação do interesse pelo estudo das "gramáticas políticas" das mobilizações coletivas, este artigo se volta para a análise das lutas pelo "direito à cidade" 1 . Nesse sentido, a questão que está no centro de nossa preocupação consiste em compreender como determinados grupos sociais - a exemplo de movimentos sociais, ONGs, partidos políticos, empresas etc. — criam narrativas que identificam e propõem soluções para problemas sociais que afetam a cidade. Para isso, utilizaremos como material empírico alguns fanzines - pequenas revistas criadas e divulgadas de forma alternativa e independente por grupos marginalizados em relação ao mercado editorial e de circulação hegemônico — produzidos pelo Coletivo Debaixo da cidade de Aracaju.

As ferramentas metodológicas utilizadas para recompor a noção de cidade elaborada pelo grupo foram os fanzines publicados durante o período de atuação do coletivo (os anos de 2013 e 2016) e que possibilitam ter acesso a certas narrativas públicas sobre a noção de cidade compartilhada pelos integrantes do coletivo. Além disso, algumas informações adquiridas através de entrevistas semiestruturadas, publicações catalogadas em perfis virtuais, conversas informais e observações diretas realizadas durante os eventos promovidos pelo coletivo, ainda que não utilizadas diretamente no artigo, contribuíram para a recomposição do enquadramento interpretativo elaborado pelo grupo. É importante ressaltar que o pluralismo metodológico tem sido um desafio enfrentado por diversos autores que analisam os movimentos sociais e, em especial, as ocupações no espaço público. 0 estudo de Alviso-Marino (2015) sobre as mobilizações no Yemen é um exemplo de como a noção de "seguir o objeto" na busca pela compreensão das ocupações exige um olhar para os repertórios mobilizados, os processos de ressignificação política do espaço, os modos como os grupos representam suas ações nas redes sociais virtuais, as trajetórias que são construídas a partir das ocupações etc. 
Assim, ainda que este artigo tenha como foco analítico as narrativas no intuito de compreender os enquadramentos elaborados pelos atores, outros tipos de fontes de material empírico acompanharam a construção do texto.

Tal Coletivo era composto por uma grande maioria de estudantes universitários e seus integrantes possuem alguns traços semelhantes que possibilitam uma caracterização social de seu perfil do grupo: em primeiro lugar, o envolvimento em expressões artísticas consideradas marginais como o punk e o hip-hop; em segundo o engajamento em partidos políticos, movimento estudantil e outros movimentos sociais mais alinhados à partidos de esquerda como o PSOL (Partido Socialismo e Liberdade) e o Movimento Não Pago; em terceiro, a crítica às estruturas de poder oficiais como os partidos políticos — baseados em experiências de engajamento anterior - a partir das ideias de manipulação, profissionalização e burocratização da política.

O Coletivo iniciou um conjunto de ações intituladas Sarau Debaixo que acontecia toda terceira terça-feira do mês, entre os anos de 2013 e início de 2017, com intervenções artísticas e políticas embaixo de um viaduto localizado em uma área central e de muita movimentação da cidade. A partir disso, ele construiu toda uma narrativa de luta pelo "direito à cidade" 2 a partir de várias pautas relacionadas aos problemas da cidade, como a mobilidade urbana, o genocídio da juventude negra e a presença dos corpos femininos e transexuais na cidade. A diversificação das pautas fazia referência não somente aos diversos fatores que compõem a cidade enquanto um problema público, mas também à rede de colaboração do Coletivo que foi composta por coletivos LGBT, midiativistas, grupos de hip-hop localizados na periferia da cidade e os acontecimentos sociais locais e nacionais que incluíam novas questões para as pautas. Sendo assim, a vinculação do Coletivo Debaixo com esses grupos também contribuiu para um processo crescente de diversificação da pauta mais geral do "direito à cidade".

0 ato de ocupar mensalmente o viaduto José de Carvalho Déda, mais conhecido como viaduto do DIA, por estar localizado no Distrito Industrial de Aracaju, ocorria através de um uso não negociado do espaço do viaduto - uma das características de intervenções ou ocupações que ocorrem sem a aprovação prévia de instâncias do Estado -, constituindo para eles uma dessas demonstrações de que é preciso se apropriar de uma cidade repartida e privatizada. 0 local escolhido era estratégico e simbólico: o viaduto do DIA, que fica localizado entre duas avenidas principais e ao lado de um dos terminais de ônibus mais movimentados no horário em que ocorria o Sarau Debaixo, um supermercado e o maior teatro local, o Teatro Tobias Barreto. Entre esses espaços, o Sarau Debaixo ocorria em um estacionamento não utilizado, e 
a escolha do Coletivo em mobilizar esse espaço era simbólica à proporção em que resgatava um dos locais mais utilizados para a contestação nas manifestações de junho de 2013, mas também por considerarem um espaço sem "função social" . Além do Sarau Debaixo, outros repertórios de ação mais simbólicos foram utilizados pelo Coletivo como a produção de vídeos e materiais impressos, nos quais, através da poesia, da música e da encenação teatral, também construíram uma narrativa sobre a cidade.

Na cidade de Aracaju, semelhante ao que estava ocorrendo em outras cidades do país, alguns acontecimentos e situações que antecederam a emergência do Coletivo Debaixo contribuíram para o processo de mobilização dessa noção de cidade pelo grupo. Primeiro, os debates que ocorreram em torno da causa pública das condições e gratuidade do transporte público através, primeiramente, do Movimento Passe Livre e depois do Movimento Não Pago, e a participação de alguns militantes no Fórum Social Mundial de 2005, que constituiu um marco importante para as pautas do transporte público. Segundo, a circulação dos idealizadores do Coletivo Debaixo nos movimentos de Sarau, que ocorreu em várias capitais do Brasil. No caso dos integrantes do Coletivo analisado, o Sarau Bem Black, que ocorria em Salvador, foi uma referência importante para a construção do Sarau Debaixo em Aracaju. Terceiro, os confrontos entre os manifestantes e os agentes policiais durante o ciclo de protesto de 2013. E, por fim, a reivindicação pelo aumento da oferta do número de locais destinados ao lazer gratuito frente ao processo de crescimento de espaços e opções privadas.

É importante destacar ainda que, diante do crescimento da organização da reivindicação a partir de diversos olhares - como a presença dos corpos indesejados nos espaços públicos, a luta pela moradia nos centros urbanos através de ocupações de espaços não utilizados ou a disputa pela destruição de referências patrimoniais para a construção de empreendimentos e do processo internacional de luta pelo direito à cidade -, esta pesquisa busca compreender como uma causa mais geral (e até mesmo nacional) é traduzida e apropriada localmente por determinado grupo. Semelhante a outros movimentos locais que surgem posteriormente (tais como: o Ensaio Aberto, o Coletivo Entre Becos, o Cultura da Periferia e o Arte na Praça), o Coletivo Debaixo constitui uma expressão local dessa pauta mais ampla da reivindicação do espaço público. E, diferentemente de outros modelos de ação coletiva que atuam nessa mesma causa, o Coletivo Debaixo - assim como os demais citados - são caracterizados principalmente por um perfil de atores engajados, a utilização de repertórios e narrativa específica e que se distingue de outras formas de reivindicação do direito à cidade, como, por exemplo, a luta pela moradia. 


\section{ENQUADRANDO A CIDADE NOS FANZINES: ENQUADRAMENTOS, NARRATIVAS E FATOS DE UMA CIDADE EM DISPUTA}

$\mathrm{E}$ m uma análise sobre os "portadores figurativos do significado" que compõe um protesto e outros tipos de ação coletiva, James Jasper (2016) elenca alguns elementos que ajudam a compreender o universo dos significados e das gramáticas construídas, como, por exemplo, as máximas e provérbios, as piadas, os hinos e slogans, os enquadramentos, as identidades coletivas, os personagens, as narrativas, os fatos, as regras e leis e as ideologias. Paralelamente a isso, utilizamos o conceito de enquadramento forjado inicialmente por Goffman (2012) e apropriado nos estudos sobre os movimentos sociais por Benford (1997), Benford e Snow (2000). A ideia central na utilização de ambas as propostas de análise é ampliar o escopo de possibilidades para a compreensão do processo de construção dos quadros interpretativos a partir da análise dos fanzines.

Esses "portadores figurativos do significado" são responsáveis por mobilizar sentimentos, manipular interpretações e propor uma série de regras e formas de identificação e ações individuais e coletivas. Ainda que utilizemos o termo "manipulação", o autor destaca que 0 acionamento desses elementos — que constituem a dimensão simbólica e gramatical de uma ação coletiva - não ocorre necessariamente através de princípios racionalistas e estrategistas. Se, por um lado, a estratégia pode ser um princípio de mobilização desses significados, por outro, aspectos morais e emocionais também orientam a adoção ou restrição no uso desses elementos simbólicos ${ }^{3}$.

A crítica à noção de estratégia, por vezes empresarial, da elaboração e difusão de enquadramentos interpretativos para mobilizar possíveis atores engajados e/ou popularizar uma determinada demanda enquanto modelo majoritário de usos das narrativas dos problemas públicos e dos símbolos tem dificultado a análise de outros modelos de apropriação das emoções (Benford, 1997; Benford, Snow, 2000). No fundo, a ideia utilizada neste artigo é a de que a estratégia é um tipo de mobilização desses recursos, mas que ocorre paralelamente, por exemplo, à mobilização de símbolos e narrativas que estão relacionadas com experiências de vida marcadas por relações de violência e desigualdade da/na cidade.

Os fanzines (figura 1) foram produzidos pelo Coletivo Debaixo paralelamente ao período de existência do Coletivo e de suas ações de reivindicação e luta pelo direito à cidade entre os anos de 2013 e 2016. A proposta dos fanzines era a da possibilidade de "dar voz" aos "poetas da cidade", aos "trabalhadores da cultura" e/ou aos "poetas marginais", todos esses termos utilizados pelos integrantes do grupo para se referirem a uma produção específica dentro do universo da poesia. Através dos fanzines, foram publicadas várias poesias de jovens que 
já produziam e outros que começaram a praticar essa forma de narrativa a partir do contato com o evento realizado mensalmente pelo coletivo, o Sarau Debaixo.

Figura 1 - Fanzine produzido pelo Coletivo Debaixo

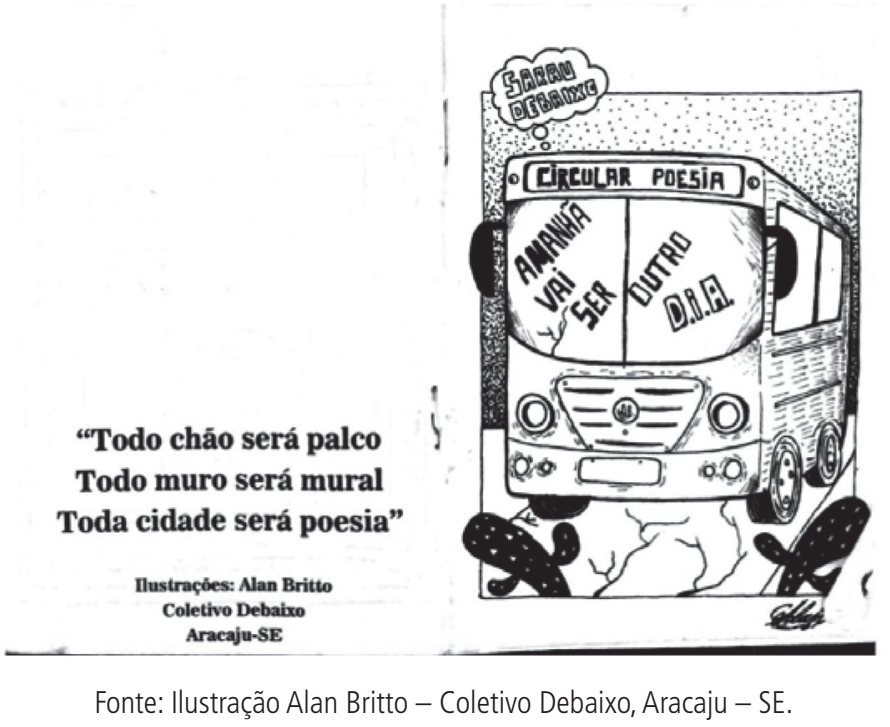

Os fanzines do Coletivo Debaixo se tornaram não somente um dos meios de divulgação de poesias marginalizadas em um circuito hegemônico de literatura, mas também um dos modos do Coletivo difundir aquilo que o grupo compreendia como "cidade", "ocupação", "política", "ação contestatória", "violência na cidade", "desigualdade na cidade" etc.

O quadrado de Pirro: uma cidade desigual, limpa e repartida

A higienização da cidade

Não é feita

Varrendo rua,

Mas sim,

Varrendo gente

Pra onde

0 roteiro turístico não passa

E nem vai passar.

Mas essa gente é

Muito mais que isso 
Pare pra ouvir

Ela vai te contar

(Poesia retirada do fanzine publicado em maio de 2015)

A expressão "quadrado de Pirro" se popularizou em Aracaju a partir da intervenção do engenheiro militar Sebastião José Basílio Pirro, que projetou, entre o final do século XIX e início do XX, a reconstrução do centro da cidade a partir de um quadrado de 32 quadras com 110 metros para cada rua. Isso construiu a imagem do centro de Aracaju que, vista de cima, parece um tabuleiro de xadrez. Todo esse processo foi construído com o interesse de modernizar e reservar um espaço para o centro comercial de Aracaju.

No entanto, esse projeto de modernização, para os integrantes do Coletivo Debaixo, constitui um dos marcos históricos de higienização do espaço público. 0 processo de higienização é interpretado fundamentalmente enquanto um processo violento de segregação que aparece, por exemplo, na poesia anteriormente citada: a higienização não ocorre varrendo rua, mas varrendo gente. Antes do trecho destacado, a poetisa também registra alguns aspectos do modo como narra a cidade:

[...] que a cidade, meus queridos...

não é só coisa linda não

pode ter certeza é muita contradição

E para torná-la menos visível

quem tem poder faz quase o impossível...

mas é pra manter os debaixo

afastados, viu

pra que sua visita seja bem confortável

Vale bater em um camelô

pra que desocupe a via, pois,

pra projeto belíssimo de cidade

qualquer discordância é rebeldia.

(Poesia retirada do fanzine publicado em maio de 2015)

As noções de "contradição", "projeto belíssimo", "afastar os debaixo" e de "rebeldia" anunciam aquilo que está na base da concepção de cidade e de ação política de luta em torno da causa. Como destacamos acima, as contradições para o Coletivo Debaixo, e que é evidenciada nesse poema do fanzine, constitui umas das qualidades utilizadas pelo grupo para definir aquilo que chamam de "cidade desigual", na qual os atores menos favorecidos, "os 
debaixo", são afastados para zonas periféricas. E é essa "desocupação das vias" que promove e permite um projeto de belíssima Aracaju.

É necessário salientar que, além das experiências de vida desses atores, a presença de um estudante do curso de Geografia da Universidade Federal de Sergipe e sua expertise também contribuíram para a construção da crítica à cidade enquanto espaço de segregação.

\section{UMA CIDADE DE MÚLTIPLAS VIOLÊNCIAS E POUCOS DIREITOS}

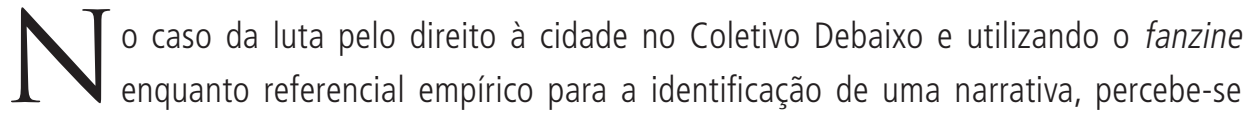
que as noções de cidade, todas como um problema social, são fragmentadas a partir das diversas experiências individuais. A noção de desigualdade aparece no tópico anterior enquanto demarcada por um espaço segregado. Agora, entramos em alguns outros elementos, relacionados com o anterior, e que constroem uma narrativa paralela de uma cidade de múltiplas violências e poucos direitos.

A rua é minha ou não é, até quando vou ter que ficar nessa de ficar andando depressa, da pressa eu tô cansada isso de andar de cabeça abaixada, de precisar tá acompanhada por um outro cara ou pro cara de pau poder me respeitar. [...]

A rua é nossa, a cidade é nossa, vou de cima a baixo, vou de bike, mas me dói muito saber que tem mulheres que saem e não voltam, pois encontram no caminho quem Ihes faça mal.

(Poesia retirada do fanzine publicado em março de 2015)

Nessa edição do fanzine de março de 2015, uma poetisa (e também integrante do Coletivo Debaixo) inclui uma nova perspectiva de luta pelo direito à cidade. Neste caso, através da ideia de um espaço público violento e agressivo com as mulheres. As violências simbólicas como 0 assédio sexual e a constante autovigilância em torno da possibilidade de ser violentada ou as violências físicas representadas pelas agressões sofridas pelas mulheres no espaço público fundamentam o diagnóstico elaborado com o protagonismo dos coletivos de mulheres sobre a cidade. Ao reivindicar as ideias de que "a rua é nossa, a cidade é nossa" e vincular essa pauta com as violências de gênero experimentadas no espaço público ao andar de bicicleta e às dificuldades em ter que circular no espaço público em qualquer horário, a poesia relaciona as problemáticas em torno da presença do corpo feminino na cidade.

As poesias a seguir trazem outras dimensões dessa noção de cidade violenta através de uma narrativa construída a partir de uma ideia fundamental que é a retirada das pessoas dos espaços públicos frente ao aumento da violência, como também a pauta amplamente reivin- 
dicada por diversos grupos em torno do debate da urbanidade e dos movimentos negros; 0 genocídio da população negra.

Construímos monumentos sobre a paisagem/ erguemos muralhas, criamos o lado de dentro/ espessam-se os muros e põe-se blindagem

$[\ldots]$

Acuados num canto/ açoitados nas costas nuas/ acuados, nos perguntamos tanto/ quem nos tirou as ruas.

(Poesia retirada da edição 14 do fanzine publicado em abril de 2015)

É muita gente de PRETO/Matando gente PRETO/ Mas no fundo tudo é PRETO/ Por conta do navio NEGREIRO/ Que ancorou no mangue PRETO/ Subiram pro morro todos os PRETOS [...]

Como quando mandaram recolher todos os mendigos PRETOS/ Da cidade mais limpa.

(Poesia retirada do fanzine publicado em abril de 2015)

As ideias de que estamos "acuados" e de que nos retiraram as ruas, o direito de estar nas ruas, como também a concepção de que "recolher todos os mendigos pretos", matar gente preta nos morros com população negra é a base da narrativa do grupo. Aqui, a violência é interpretada como um modo institucional de justificar a "limpeza da cidade".

Essa concepção de cidade é aquilo que os estudos sobre os enquadramentos identificam enquanto os frames de diagnósticos que, paralelamente aos frames de prognósticos e motivação, compõem uma tríade dos core framing talks (Benford, Snow, 2000).

Os quadros de ação coletiva são construídos em parte como aderentes do movimento que negociam uma compreensão compartilhada de alguma condição ou situação problemática que eles definem como precisando de mudança, fazem atribuições a respeito de quem ou o que é culpado, articular uma alternativa de arranjos, e induzem outros a agir em conjunto para afetar a mudança. (Benford, Snow, 2000, p. 615, tradução do autor)

Articulado a ideia de "portadores figurativos de significado" em Jasper (2016), os frames de diagnósticos, prognósticos e motivações podem ser comparados à noção mais geral de enquadramentos. Para o autor, os enquadramentos são "um tipo de metáfora subjacente que inclui o diagnóstico de um problema, sugere soluções e, com sorte, motiva a ação" (Jasper, 2016, p. 73). Nessa definição, o autor inclui as três noções do core framing talnks de Benford e Snow (2000) sintetizadas na ideia de enquadramento.

Se as noções de cidade enquanto espaço de múltiplas violências, desigual e segregada, compõem o frame de diagnóstico identificados em algumas poesias do fanzine publicado pelo Coletivo Debaixo, e várias outras poesias podem nos mostrar algumas outras interpretações 
da cidade enquanto um problema social, as poesias do fanzine também apontam para alguns prognósticos e motivações para a construção de ações coletivas.

Nesse sentido, a definição de Blumer (1971) sobre as construções dos problemas sociais enquanto um "processo de definição coletiva e não um conjunto de condições sociais objetivas existentes independentemente" nos ajuda a compreender o processo, destacado aqui a partir da ideia de enquadramento, de mobilização de recursos simbólicos e ações contestatórias para a construção da cidade enquanto um problema social.

No próximo tópico destacamos como a concepção desse problema social específico e os processos de reivindicação se tornam, para o Coletivo Debaixo, uma oportunidade de construir modelos de resolução desse problema através da ocupação cultural da cidade.

\title{
A OCUPAÇÃO CULTURAL DO ESPAÇO PÚBLICO ENQUANTO PRÁTICA DE CONTESTAÇÃO
}

\begin{abstract}
Imagina como a cidade seria diferente se mensalmente duas bandas daqui se apresentassem de graça no Atheneu, se a cada segunda-feira um espetáculo teatral ou de dança se apresentasse no final de linha do Augusto Franco. Se na terça-feira fosse dia de cinema ao ar livre no Bugio, na quarta um recitam em baixo da Aracaju-Barra [ponte, grifo do autor] e assim por diante ocupando a cidade com cultura. Dá pra imaginar o quanto isso mexeria direta ou indiretamente com a vida das pessoas?
\end{abstract} (Texto de integrante do Bagaceira Talhada retirado do fanzine publicado em março de 2015)

No tópico anterior, destacamos o que os estudos sobre os enquadramentos interpretativos identificam enquanto os frames de diagnóstico. Agora, ainda baseado em textos publicados nos fanzines publicados pelo Coletivo Debaixo e em algumas entrevistas publicadas em sites eletrônicos ${ }^{4}$ analisamos os frames de prognóstico e de motivação. Os frames de prognóstico se referem ao momento posterior ao diagnóstico do problema em que os diferentes grupos identificam as possíveis soluções e motivações para a construção de uma ação coletiva.

No entanto, antes de destacar o prognóstico, é necessário salientar que o blog Bagaceira Talhada foi fundamental para a divulgação do Sarau Debaixo e do Coletivo Debaixo. Além disso, o blog - que também era um coletivo de midiativista - compunha um dos parceiros da "rede de colaboradores", termo utilizado por alguns integrantes do Coletivo Debaixo para se referir ao modo mais horizontalizado que estabelecia com outras organizações e que caracterizava a dinâmica do "coletivo" enquanto um modelo organizacional. 
0 texto retirado do blog Bagaceira Talhada nos ajuda a compreender a escolha dos modelos de ação coletiva construídos por parte desses coletivos culturais que se inserem nessa pauta. A partir disso, a ideia de "ocupar a cidade com cultura" enquanto uma representação da discordância dos modos tradicionais de organização da cidade emerge como modelo de contestação utilizado pelo Coletivo Debaixo. Sendo assim, a ocupação seria não somente o frame de prognóstico como também o repertório de ação contestatória mobilizado pelo grupo.

Existem várias representações do 'concreto acomodado' da cidade por ali: o maior teatro da capital, vizinho do viaduto, que nasceu para ser o templo sagrado da cultura sergipana é, na verdade, carente de algo que Ihe preencha com sustância; sem falar do ritmo frenético do cotidiano das pessoas que passam por ali, tudo precisa ser rápido, geométrico e sem contato. Sendo assim, aquelas estruturas rígidas de cimento caracterizam o nosso espaço divergente, o nosso espaço na luta de ressignificar uma cidade que se esqueceu de nós, o nosso espaço de retomar com arte, onde poesia, música, rima, grafite, teatro, dança e cinema estejam no comando das coisas. (PRATA, 2015, p. 1)

A ideia de ocupar a cidade com cultura é central no prognóstico dos atores engajados, principalmente no que se refere à construção de modelos de ação contestatória. A concepção de que o espaço público é composto por "estruturas rígidas de cimento" de "concreto acomodado" e a possibilidade de criar um espaço diferenciado (as ocupações culturais e os saraus são alguns exemplos) com novas regras de dominação, ainda que seja momentaneamente, constitui um dos modos de ressignificação dos espaços.

Alguns estudos têm revelado como o processo de reivindicação da cidade ocorre paralelamente ao uso da ocupação enquanto o modelo de ação mobilizado pelos grupos dentro e fora do Brasil (Maricato, 2013; Dechezelles, Olive, 2017; Combes et al. 2016). A disputa do espaço público acontece a partir de múltiplas práticas paralelas às ocupações; entre elas, 0 que buscamos destacar neste artigo é a construção de uma narrativa sobre a cidade. Com isso, é possível ir além da constatação internacional sobre esse universo de constatação e compreender como tais questões são traduzidas, ainda que esteja vinculada a questões internacionais em um nível local.

Paralelamente à construção de novos espaços dentro da cidade que resultam, por exemplo, das ocupações organizadas por esses coletivos, esses grupos trazem em suas narrativas a ideia da cidade enquanto um "espaço divergente", um "espaço de luta", um espaço a ser "retomado" no qual a arte "esteja no comando das coisas" e não os projetos de higienização e modernização ou a violência destacada anteriormente. Com base nesse prognóstico já ressaltado, emerge um conjunto de ocupações em Aracaju, região metropolitana, e em algumas 
cidades do interior do estado. Todas com um discurso semelhante: a ideia de que é preciso retomar a cidade. Esse enquadramento também vai sendo adaptado a partir dos diversos contextos e dos grupos que se apropriam dele. Por exemplo, alguns grupos focam na ideia de que é preciso criar espaços de lazer na periferia e outros de que a pauta principal é a democratização da cultura. No entanto, diante dessa diversidade de propostas de pauta, a centralidade na ideia de que a cidade é um direito permanece nas mobilizações.

A partir disso, as ocupações são um modelo de contestação por onde se materializam essas indignações. No caso do Sarau Debaixo, o coletivo inicia uma rotina de ocupação mensal por onde vários outros atores e grupos como juventudes partidárias e movimentos sociais experimentam essa forma de se fazer política. É importante ressaltar que, ainda que tenhamos focado a análise em algumas dinâmicas locais, como mostra Maricato (2013) e Harvey (2012) há, em níveis nacional e internacional, um conjunto de experiências semelhantes. Inclusive, como já salientamos anteriormente, a própria trajetória do Coletivo Debaixo e a idealização do Sarau a partir de alguns contatos anteriores de atores com o "movimento de sarau" 5 já explicitam a relação entre esses "ocupas"6.

Em suma, buscamos destacar neste tópico que é a concepção da cidade enquanto um espaço de disputa política, muito presente na ideia de ação contestatória no Coletivo Debaixo, que compõe o discurso motivador na construção de ações contestatórias como o Sarau Debaixo e várias outras experiências de ocupação do espaço público.

\section{CONCLUSÃO}

proposta deste artigo foi analisar os processos de construção de gramáticas de contes-
tação pelos movimentos sociais. Assim, a importância deste artigo se relaciona à compreensão, no âmbito dos coletivos que reivindicam o espaço público, dos elementos simbólicos que compõem a narrativa da cidade enquanto um problema social e, a partir disso, constroem uma demanda. Este trabalho pretende ir além dos estudos recentes sobre os movimentos sociais em disputa nesta pauta, que enfatiza dois aspectos relevantes: a ressignificação física dos espaços através da construção de uma rotina de contestação e a relação entre as causas estruturais das desigualdades urbanas e a emergência das ações coletivas. Isso porque nossas reflexões sugerem que a relação entre as experiências de vida e a pauta mais ampla do "direito à cidade" é uma chave analítica para compreender o processo de diversificação do que tem sido mobilizado desde a tradicional luta pela moradia no Brasil. Todavia, elas estão articuladas também às mobilizações de grupos e coletivos de mulheres, feministas e/ou LGBT que reivindicam a igualdade na mobilidade dos corpos, como também dos jovens periféricos que 
exigem uma cidade cuja violência não atinja exclusivamente a população negra e periférica e os equipamentos (como praças ou parques) também sejam implantados nas zonas periféricas.

Diante do amplo e fragmentado arcabouço teórico dos estudos sobre enquadramento interpretativos no campo de pesquisa sobre os movimentos sociais ${ }^{7}$, a proposta deste artigo foi a de perseguir alguns materiais públicos produzidos pelo Coletivo Debaixo para compreender o modo como o grupo "enquadrou" a cidade na construção desse processo de reivindicação. 0 material empírico utilizado foi quase que exclusivamente os fanzines produzidos entre 2013 e 2016, período de mobilização do coletivo, e uma entrevista publicada em site eletrônico.

A partir dos conceitos de frames de diagnóstico, prognóstico e motivação, reunimos algumas narrativas que são pertinentes ao Coletivo Debaixo na construção de uma concepção da cidade enquanto um problema social. A dupla categorização da cidade caracterizada, de um lado, pela segregação e higienização e, de outro, pela violência à grupos vulneráveis (as mulheres, os jovens negros e os LGBT), está na base do frame de diagnóstico que fundamenta e justifica a necessidade de um conjunto de ações e medidas organizadas pelo grupo. Já o frame de prognóstico elaborado pelo coletivo mobiliza a "metáfora" da cidade enquanto um espaço divergente e de disputa política.

No entanto, é importante destacar que os quadros interpretativos não são elaborações eminentemente individuais, e sim produtos sociais. Essa é uma das críticas que Benford (1997) e Benford, Snow (2000), ambos expoentes da análise dos frames nos estudos sobre movimentos, fazem ao desenvolvimento a partir de uma revisão "de dentro" desse campo de investigação. Para esses autores, os estudos dos frames na sociologia da ação coletiva utilizaram critérios individuais e demasiadamente "psicologizantes" para a explicação dos fenômenos sociais. Parte disso ocorre através da abertura à interdisciplinaridade com a área da Psicologia Social - inclusive a relação com outros campos de estudo é uma reivindicação presente na análise de frames - e, com isso, a dimensão coletiva tornou um elemento secundário no estudo dos quadros interpretativos.

A segunda crítica elencada por Benford (1997) e outros autores como Mathieu (2002) e Cefaï (2009), estes últimos vinculados ao pragmatismo francês, é que a teoria dos enquadramentos interpretativos elaborou, ao longo do desenvolvimento da proposta, um arcabouço teórico bastante vinculado a uma visão estratégica e utilitarista da ação coletiva. Em parte, isso é uma consequência da concentração das pesquisas em investigar como as lideranças criavam enquadramentos com capacidade de mobilizar possíveis atores engajados e/ou difusão e popularização das causas. Diante dessa crítica, este artigo busca dialogar com esse desafio teórico e empírico através da compreensão do enquadramento não somente enquanto 
uma possibilidade de disputar uma causa, a reivindicação do direito à cidade, mas também como uma forma dos atores estabelecerem sentido para o engajamento nesse tipo de mobilização. Para isso, como buscamos demonstrar através das narrativas identificadas nos fanzines, os sentimentos de violação de direitos na circulação do espaço público constituem um dos elementos que unem os enquadramentos coletivos e as experiências de vida dos atores. Sendo assim, para além de uma visão estratégica, o artigo buscou compreender os elementos simbólicos que compõem os enquadramentos e, através da vinculação dos atores às molduras elaboradas pelo coletivo, possibilita o engajamento.

Em diálogo com isso, buscamos demonstrar que os frames elaborados no Coletivo Debaixo estão relacionados a alguns "fatos". Os fatos no esquema dos "portadores figurativos de significado" em Jasper (2016) correspondem às interpretações que os atores e grupos criam a partir de uma realidade empírica e introduzem enquanto um elemento da narrativa. Sendo assim, os frames são interpretações e narrativas coletivas onde é possível também encontrar traduções individuais para o mesmo enquadramento. 0 exemplo da presença de uma reivindicação do direito à cidade a partir da condição de um jovem negro ou uma mulher é um dos modos em que percebemos o cruzamento entre as histórias de vida individuais e um enquadramento coletivo, que é o "direito à cidade". No caso do Coletivo Debaixo, é bastante evidente como as poesias e outros tipos de intervenção sobre o "direito à cidade" e as violências de gênero são demarcadas por experiências femininas de vida na cidade.

Sendo assim, são fundamentais para compreender a emergência dos frames as motivações para a ação e os processos de engajamento, as conexões entre fatos empíricos relativamente diversificados, tais como a luta em torno da mobilidade urbana através da campanha contra o aumento da tarifa protagonizada em Aracaju pelo movimento Não Pago, o debate promovido por um professor universitário com o título de "Desobediência Civil e Transporte Público" 8 , os intensos conflitos entre instâncias policiais e os manifestantes que reivindicavam o direito de protestar e "ocupar" as ruas e as experiências de vida dos integrantes e idealizadores do coletivo em outros movimentos de ocupação em Salvador como Sarau Bem Black, entre outros.

Em artigo recente sobre o desenvolvimento da perspectiva das análises de frames e a recepção dessa abordagem nos estudos sobre os movimentos sociais no Brasil, Silva (et al. 2017), destaca a capacidade da teoria do enquadramento para a problematização de alguns temas de pesquisa bastante ideologizados como a relação entre movimentos sociais e as mídias e as disputas internas e externas em torno das narrativas sobre questões, pautas e/ ou problemas sociais. Em consonância com isso, entendemos que os estudos dos quadros interpretativos também são fundamentais, paralelamente a alguns princípios etnográficos dos 
estudos pragmatistas sobre as gramáticas e justificações (Cefaï, 2007, 2009; Oliveira, 2015), para a imersão do pesquisador na busca pela compreensão das concepções políticas compartilhada por grupos.

Além disso, nos últimos anos, os estudos sobre movimentos sociais e a luta pelo direito à cidade têm analisado a relação entre os "novos" tipos de reivindicação do espaço público enquanto diferentes experiências de um ciclo global de protestos (Maricato, 2013; Dechezelles, Olive, 2017; Combes et al. 2016). Diante desse cenário, a perspectiva adotada neste artigo se insere em uma abordagem que busca compreender as traduções locais desses "problemas globais". Nesse sentido, a proposta de realizar uma imersão etnográfica permitiu compreender o processo de construção de um conjunto de concepções compartilhadas pelo grupo sobre política, ação contestatória e "direito à cidade". E, a partir da crítica realizada por Benford (1997) às abordagens individualistas e "psicologizantes" dos enquadramentos, demonstramos como essas molduras interpretativas são elaboradas paralelamente a um conjunto de experiências individuais presentes nas histórias de vida que motivam o engajamento, e também aos acontecimentos coletivos como debates sobre formas de rebeldia e mobilidade urbana, a difusão da ocupação do espaço público enquanto modelo de ação contestatória e, por fim, a participação nas manifestações de junho de 2013, acompanhada dos enfrentamentos entre os policiais e os movimentos sociais.

Portanto, ainda que o artigo problematize o processo de construção dos enquadramentos interpretativos em torno da luta pelo direito à cidade, o cenário de mobilizações após o fim do Coletivo Debaixo contribui para uma ampla agenda de pesquisa como a investigação do processo de difusão de um modo de contestação, o desenvolvimento de novos enquadramentos e a apropriação dessa narrativa da cidade por outros coletivos com diferentes perfis de atores, a transformação desse tipo de ação contestatória em política pública através do projeto Ocupe a Praça recentemente desenvolvido pela prefeitura de Aracaju e como cada uma dessas ocupações passam a ser consideradas enquanto espaços de representação política tendo em vista que as juventudes partidárias se apropriaram da ocupação enquanto não somente repertório de contestação mas também espaço de socialização política. 


\section{NOTAS}

1 Este artigo é resultado de uma dissertação apresentada sob o título "As manifestações de junho de 2013 pra gente não acabou": um estudo sobre as formas de contestação no Coletivo Debaixo em Aracaju (Santos, 2017).

2 É necessário salientar que a expressão "direito à cidade", por vezes, também é utilizada paralelamente ao uso teórico elaborado por Lefebvre (2001), autor responsável pela criação do termo que acaba de completar 50 anos.

3 Ver as críticas do autor sobre a ausência das dimensões da emoção na teoria da ação coletiva (Jasper, 2010; Jasper, Goodwin, 1999).

4 A utilização de entrevistas ocorreu devido ao pouco material em que podemos identificar prognósticos na luta pelo direito à cidade nos fanzines.

50 "movimento de sarau" é a forma como os atores identificam o circuito de Saraus por várias cidades do Brasil.

60 termo "ocupas" tem sido utilizado por alguns militantes para se referir às ocupações.

7 Ver a crítica de Benford (1997) ao desenvolvimento das análises de frames.

8 Ver a matéria em <http://g1.globo.com/se/sergipe/noticia/2013/07/quatro-homens-sao-detidos-durante-manifestacao-em-aracaju.html>.

\section{REFERÊNCIAS BIBLIOGRÁFICAS}

ALONSO, Angela. As teorias dos movimentos sociais: um balanço do debate. Lua Nova (São Paulo), n. 76, n. 1, 2009.

ALVISO-MARINO, Anahi. Faire d'un lieu un symbolique politique: la photographie engagée sur la Place du Changement à Sanaa. Les lieux de la colère: occuper l'espace pou contester, de Madrid à Sanaa. Karthala Editeur, 2015, p. 35-71.

BENFORD, Robert. D. An insider's critique of the social movement framing perspective. Sociological inquiry (Austin), v. 67, n. 4, 1997.

; SNOW, David A. Framing processes and social movements: an overview and assessment. Annual review of sociology, v. 26, n. 1, 2000.

CEFAÏ, Daniel. Introduction générale. Porquoi se mobilise-t-on? Les théories de l'action collective. Paris: La Découverte, 2007.

Como nos mobilizamos? A contribuição de uma abordagem pragmatista para a sociologia da ação coletiva. Dilemas: Revista de Estudos de Conflito e Controle Social (Rio de Janeiro), v. 2, n. 4, 2009.

COMBES, Hélène; GARIBAY, David; GOIRAND, Camile. Les lieux de la colère. Occuper l'espace pour contester, de Madrid à Sanna. Paris: Karthala, 2016. 
DECHEZELLES, Séphanie.; OLIVE, Maurice. Les mouvements d'occupation: agir, protester, critique. Politix (Paris), v. 30, n. 117, 2017.

DIANI, Mario. The concept of social movement. The sociological review (Londres), v. 40, n. 1, 1992.

; DELLA PORTA, Donatella. Social movements: an introduction. Oxford: Blackwell Publishing, 2006.

GOFFMAN, Erving. Os quadros da experiência social: uma perspectiva de análise. Petrópolis: Vozes, 2012.

GOHN, Maria da Glória. Teoria dos movimentos sociais: paradigmas clássicos e contemporâneos. São Paulo: Edições Loyola, 2014.

JASPER, James M. Protesto: uma introdução aos movimentos sociais. Rio de Janeiro: Editora Zahar, 2016.

2010. Social movement theory today: toward a theory of action? Sociology compass, Oxford, vol. 4, n. 11, ; GOODWIN, Jeff. Caugh in a widing, snarling vine: the structural bias of political process theory. Sociological Forum (Nova lorque), v. 14, n. 1, 1999.

LEFEBVRE, Henry. O direito à cidade. São Paulo: Centauro, 2001.

MARICATO, Erminia. Cidades rebeldes: Passe Livre e as manifestações que tomaram as ruas do Brasil. São Paulo: Boitempo, 2013.

MATHIEU, Lilian. Rapport au politique, dimensions cognitives et perspectives pragmatiques dans l'analyse des mouvements sociaux. Revue Française de Science Politique (Paris), v. 52, n. 1, 2002.

OLIVEIRA, Wilson. José. Ferreira de. Posição de Classe, Redes e Carreiras Militantes. Revista Brasileira de Ciência Política (Brasília), n. 3, 2010.

A Arte de Resistir às Palavras: inserção social, engajamento político e militância múltipla. In: SEIDL, E.; GRILL, I. G. (Org.). As ciências sociais e os espaços da política no Brasil. 1. ed. Rio de Janeiro: FGV Editora, 2013.

Antropologia, política e etnografia: entre fronteiras disciplinares e problemas empíricos. In: PERISSINOTTO, R.; CODATO, A. N. (Org.). Como estudar elites. 1. ed. Curitiba: Editora UFPR, 2015, p. 187-214.

SANTOS, Jonatha Vasconcelos. "As manifestações de junho pra gente não acabou": um estudo sobre as formas de contestação no Coletivo Debaixo em Aracaju. 2017. 149 f. Dissertação (Mestrado em Sociologia). Universidade Federal de Sergipe, 2017.

SILVA, Marcelo Kunrath; COTANDA, Fernando Coutinho; PEREIRA, Matheus Mazzilli. Interpretação e ação coletiva: o "enquadramento interpretativo" no estudo de movimentos sociais. Revista de sociologia e política (Curitiba), v. 25, n. 61, 2017.

Quatro homens são detidos durante manifestação em Aracaju. G1 Sergipe, Aracaju, jul. 2013. Disponível em <http://g1.globo.com/se/sergipe/noticia/2013/07/quatro-homens-sao-detidos-durante-manifestacao-em-aracaju.html>. Acesso em: 20 abr. 2016.

PRATA, Lucas. A força que vem debaixo. Redbull Amaphiko. Brasil, set. 2015. Disponível em <https://amaphiko.redbull.com/pt-BR/magazine/a-forca-que-vem-debaixo>. Acesso em: 20 mai. 2016. 